\title{
Single Neuron Responses in Amygdala of Alert Monkey During Complex Sensory Stimulation with Affective Significance
}

\author{
H. Nishijo, T. Ono, and H. Nishino \\ Department of Physiology, Faculty of Medicine, Toyama Medical and Pharmaceutical University, Toyama 930-01, Japan
}

Among other deficits, amygdalectomy impairs the ability of the animal to recognize the affective significance of a stimulus. In the present study, neuronal activity in the amygdala (AM) was recorded from alert monkeys while they performed tasks leading to the presentation of rewarding or aversive stimuli. Of 585 AM neurons tested, $312(53.3 \%)$ responded to at least one stimulus in one or more of 5 major groups: 40 vision related, 26 audition related, 41 ingestion related, 117 multimodal, and 14 selective. Ingestion-related neurons were subdivided according to their responses to other stimuli: oral sensory, oral sensory plus vision, and oral sensory plus audition. Depending upon their responsiveness to the affective significance of the stimuli, neurons in the visionand audition-related categories were divided into 2 subclasses: vis-I (26/40), vis-II (14/40), aud-I (8/26), and aud-II $(18 / 26)$. All 4 subtypes usually responded to unfamiliar stimuli but seldom responded to neutral familiar stimuli. Types vis-I and aud-I responded to both positive and negative familiar stimuli. Types vis-1I and aud-II responded to certain familiar negative stimuli but not to familiar positive stimuli. In vis-I neurons, responses were stronger for palatable foods than for less palatable foods. No neurons within vision-related, audition-related, and multimodal categories responded solely to positive or to negative stimuli. Of the 27 oral sensory neurons 9 were tested with saline or salted food, and 8 responded to normally aversive oral sensory stimuli in the same manner as they did to normal food or liquid (water or juice). In contrast to oral sensory neurons, all responses of 4 oral sensory-plus-vision and all of 4 selective neurons tested, as well as bar pressing behavior, were modulated by altering the affective significance of the food. These results suggest that the AM is one of the candidates for stimulusaffective association based on associative learning and memory.

Highly processed sensory information from all modalities converge on the amygdala (AM) (Gloor, 1960; Turner et al., 1980; Iwai and Yukie, 1987). In turn, the AM projects to the hypothalamus (Oomura et al., 1970; Krettek and Price, 1978; Amaral

\footnotetext{
Received Nov. 18, 1987; accepted Jan. 22, 1988.

We thank Dr. R. Norgren, Pennsylvania State University; Dr. A. Simpson, Showa University for advice and help with the manuscript; Dr. E. Iwai, Tokyo Metropolitan Institute for Neurosciences, for advice on the terminology of the amygdala; and Miss A. Hatayama for typing. This work was supported partly by the Japanese Ministry of Education, Science and Culture Grants-in-Aid for Scientific Research 60440028 and 60216010.

Correspondence should be addressed to Prof. Taketoshi Ono, M.D., Ph.D., at the above address.

Copyright $@ 1988$ Society for Neuroscience $0270-6474 / 88 / 103570-14 \$ 02.00 / 0$
}

et al., 1982; Ono et al., 1985), which is essential for emotional behavior (Oomura, 1980; Isaacson, 1982). Electrical stimulation of the AM elicits defense and flight reactions in cat (Kaada, 1972) and feelings of fear, rage, and confusion in man (Chapman et al., 1954; Heath et al., 1955). Bilateral lesions of the temporal cortex that include the AM produce the Klüver-Bucy syndrome (tameness, hypersexuality, visual agnosia, and oral tendency) in the monkey (Klüver and Bucy, 1939; Weiskrantz, 1956; Gloor, 1960; Horel et al., 1975). Recent studies suggest that the AM is also involved in functions such as attention or general arousal (Goddard, 1964; Pribram and McGuinness, 1975) and mnemonic and cognitive functions (Mishkin, 1978, 1982; Mishkin and Aggleton, 1981; Zola-Morgan et al., 1982; Sarter and Markowitsch, 1985), as well as positive and negative affective reactions or behavior (Goddard, 1964; Kaada, 1972; Isaacson, 1982) such as feeding, drinking, sexual behavior, learned taste aversion, and avoidance.

To account for some of these relations, one hypothesis holds that the AM might be involved in the process through which sensory stimuli gain motivational and emotional significance through interaction between the higher sensory cortex and the limbic system, i.e., stimulus-affective association (Weiskrantz, 1956; Jones and Mishkin, 1972; Spiegler and Mishkin, 1981). Bilateral lesions of the monkey AM or temporal cortex produce visual-limbic disconnection (Geschwind, 1965) or sensory-affective dissociation (Jones and Mishkin, 1972), which is suggested to be the underlying defect responsible for the KlüverBucy syndrome. In other words, the lesioned subjects cannot recognize the significance of stimuli (Weiskrantz, 1956).

Single-unit recording in alert animals has revealed AM neuronal responses to complex stimuli such as food, syringe, cotton, human face, and black mouse shapes (O'Keefe and Bouma, 1969; Jacobs and McGinty, 1972; Sanghera et al., 1979; Ono et al., 1980, 1983; Nakano et al., 1987). The stimulusaffective dissociation that follows AM lesions implies the existence of units that might respond to affective significance of stimuli rather than their sensory characteristics (Mishkin and Aggleton, 1981). One previous unit recording study, however, reported that AM neurons neither responded only to positive or negative stimuli in that AM neurons responded to certain objects with opposite significance, although those neurons responded primarily to positive or negative stimuli, nor changed firing rates by alteration of affective significance of the stimuli (Sanghera et al., 1979).

The objective of the present study was to determine whether the neuronal response to a given stimulus depended on the rewarding or aversive significance of that stimulus. To this end, we presented monkeys with stimuli in experimental situations that could be presumed to have emotional correlates and fo- 
cused attention on the possible discharge patterns that one neuron might exhibit in these different affective situations. Some of these stimuli were biologically significant and some were not (Weiskrantz, 1956; Horel et al., 1975; Perrett et al., 1982). The visual signals associated with aversive stimuli may themselves come to elicit fear (McGowan et al., 1972) or aversion (negative affective situation), and those associated with juice or food are rewarding for food- and water-deprived animals (positive affective situation). In the preceding paper, we grouped AM neurons into 5 categories based on their sensory responses. In the present study using the same monkeys and same sample of neurons as in the preceding paper (see Nishijo et al., 1988) we analyzed characteristics of each type neuron in terms of affective significance of the stimuli presented and report that some AM neurons responded only to positive or negative stimuli, and those responses were modulated by alteration of affective significance.

\section{Materials and Methods}

The experimental methods and the sample of neurons used in this study were the same as those described in the preceding paper. Various visual, auditory, oral sensory, and somesthetic stimuli with positive or negative affective significance were presented to the monkey. The previous electrophysiological studies reported that AM neurons responded to rather complex sensory stimuli with biological significance (Sawa and Delgado, 1963; O'Keefe and Bouma, 1969; Jacobs and McGinty, 1972). In the present study, various complex sensory stimuli were also introduced, and neuronal responses were analyzed in terms of affective significance of the stimuli. Combination and sequence of presented stimuli were similar to those of the preceding paper. Determination of excitatory or inhibitory responses and comparisons between responses were made by analysis of variance (ANOVA, $p<0.01$ ).

Characteristics of stimuli presented. Visual stimuli were presented in every trial, except in tests for the effect of shutter movement when the turntable was left empty. Food stimuli consisted of 10 kinds of familiar food or reward-related objects (cookie, raisin, orange, jellybean, apple, potato, watermelon, cabbage, and the red or white cylinder associated with water or juice), which were used in the training and experimental sessions, 10 kinds of unfamiliar real foods, and 30 kinds of unfamiliar imitation foods. Familiar nonfood stimuli included tape, glove, syringe, white mouse model, frog model, beetle model, snake model, wooden rectangular parallelepiped, and brown cylinder associated with electric shock. More than 600 kinds of unfamiliar nonfood objects, including imitations of certain insects and animals, were used. Some unfamiliar food and/or unfamiliar imitation foods and/or unfamiliar nonfood objects were randomly selected for testing whenever a viable neuron was found. An unfamiliar stimulus was used in no more than 4 sets of 3 or 4 trials for one monkey throughout the experiments, and some were used in only one set.

Familiar food and potables are assumed to be rewarding for foodand water-deprived animals. Preference for the familiar foods was first tested separately from unit recording experiments. When satiated with regular laboratory chow, monkeys did not ingest or pick up foods such as a raisin or a cookie, but the animals quickly took watermelon, apple, orange, or potato. Therefore, these last 4 foods were considered to be preferred. In other studies, some nonfood objects have been determined to be aversive or arousing stimuli (Weiskrantz, 1956; Horel et al., 1975; Perrett et al., 1982). Deficits in behavioral responses to these objects have been reported in amygdalectomized monkeys (Weiskrantz, 1956; Horel et al., 1975). These objects, and others that we introduced (including a glove, a syringe, a white mouse model, a frog model, a beetle model, a snake model, and others), elicited behavioral responses such as mouth opening, shaking of the monkey chair, and galvanic skin response, or head turning (in separate behavioral tests). Based on the studies cited, and verification by our own observations, these nonfood stimuli were considered to be aversive. The affective significance of these stimuli was classified into 4 categories: unfamiliar, familiar positive (rewarding), familiar negative (aversive or punishing), and familiar ncutral (Table 1). For cach ncuron tested, at least onc stimulus was presented from each of 10 categories in Table 1. Stimuli from the 11th category, familiar negative oral sensory stimuli (salted food and saline), were usually introduced only when a selective response to food or an ingestion-related response was observed (reversal test).

Modulation of affective significance of stimuli. Once a neuron had been classified on the basis of its responsiveness to a battery of sensory stimuli, the affective significance of some of these stimuli was altered in reversal or extinction trials. In reversal tests, salt was carefully put in, or on, the back of food so both salted and normal food appeared similar, or saline was associated with the red or white cylinder that was usually associatcd with watcr or juicc. In cxtinction tests, a cuc signal or the sight of food was presented without available reward. In some cases weak electric shock was associated with the stimuli presented to the animal. During these sessions the monkey's gaze was carefully monitored, and a trial was started when the animal was judged to be looking toward the window. If the electrooculogram (EOG) showed that this was not so, the data were discarded.

\section{Results}

As reported in the preceding paper, of $585 \mathrm{AM}$ neurons tested by various stimuli with or without affective significance, 312 $(53.3 \%)$ responded in some phase(s) of the operant tasks. Based on their responsiveness to sensory modalities, 238 of these 312 neurons fell into 5 major categories-vision related, audition related, ingestion related, multimodal, and selective. Two groups, the vision- and audition-related categories, were each further divided into 2 classes: vis-I, vis-II, aud-I, and aud-II. Types vis-I and aud-I responded to familiar stimuli, both positive and negative. Types vis-II and aud-II responded to specific familiar negative stimuli but not to familiar positive stimuli. All 4 subtypes usually responded to unfamiliar stimuli but seldom responded to familiar neutral stimuli. In the vision- and auditionrelated categories, none of the neurons responded only to familiar positive or to familiar negative stimuli.

\section{Vision-related neurons}

There were 40 neurons (6.8\%) that responded (all excited) to visual stimuli but not to auditory, oral sensory, or somesthetic stimuli. These neurons were functionally divided into 2 groups according to their responsiveness to familiar positive (food), familiar negative (certain nonfood), and familiar neutral (tape and shutter open) items. Vis-I neurons responded strongly to the sight of familiar, preferred food (cookie or raisin), as well as to certain familiar aversive nonfood items, but much less so to familiar neutral nonfood stimuli (tape or shutter movement) (ANOVA, $p<0.01$ ). Vis-II neurons, on the other hand, responses to familiar food and familiar neutral nonfood were not significantly different. Of the 40 vision-related neurons, 26 were classified as vis-I and 14 as vis-II. Regardless of whether the stimuli presented were food or nonfood, both categories of neurons responded strongly to the sight of unfamiliar objects and to the sight of some familiar aversive nonfood objects. Among the familiar nonfood objects that influenced the activity of these neurons were a glove, a syringe, and a mouse model. Based on the monkey's overt behavior (described in Materials and Methods), the sight of these stimuli was judged to be aversive. In addition, all the vision-related neurons habituated rapidly with repeated trials of some unfamiliar visual stimuli.

Responses of vis-I neuron to various food and nonfood objects are compared in Figure 1A. Solid circles connected by heavy lines indicate the mean firing rate in each trial for $5 \mathrm{sec}$ after W1 was opened in 4 repeated trials. Each histogram shows the mean of each $5 \mathrm{sec}$ mean firing rate after the indicated objects were revealed. The response magnitude was significantly different in response to different objects (ANOVA, $p<0.001$ ). The neuron responded strongly to unfamiliar objects (dried yam 


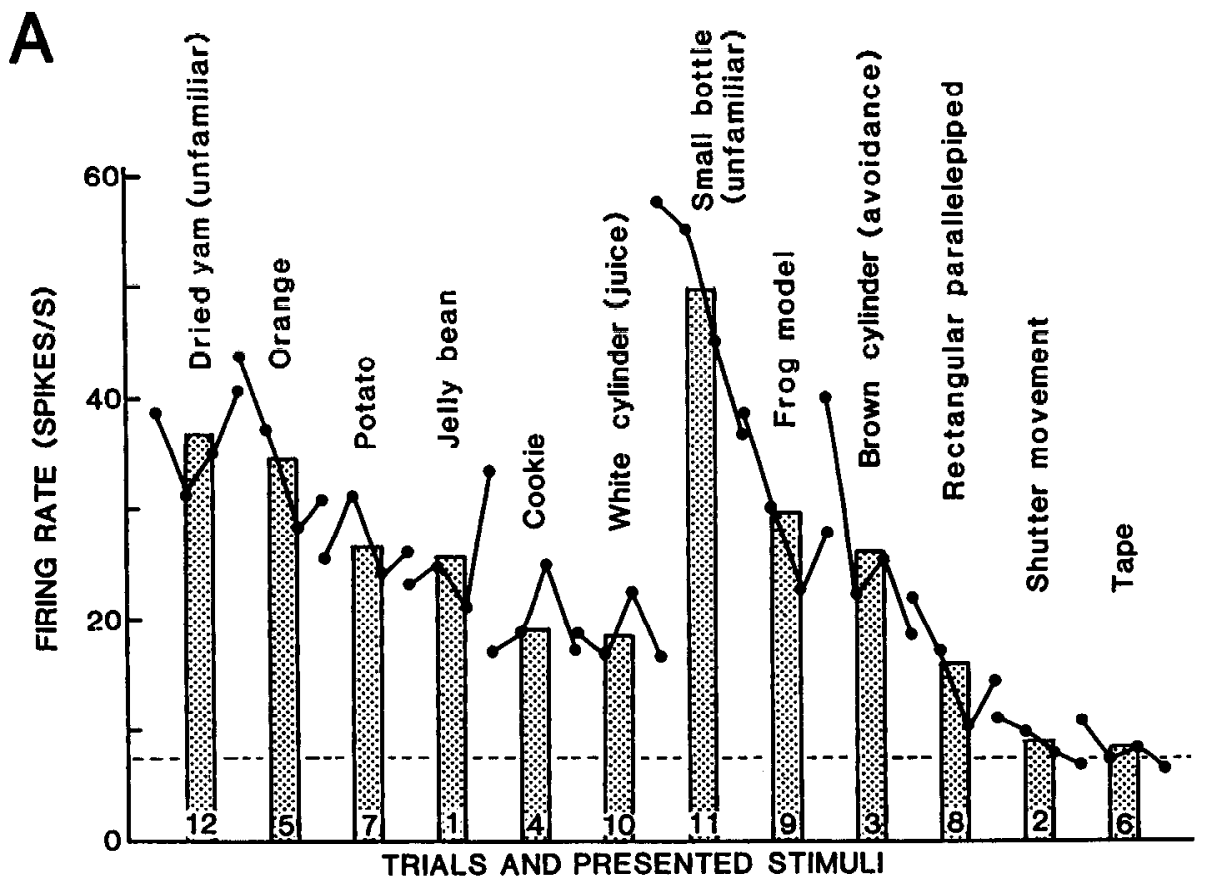

Figure 1. Comparison of vision-related neuron responses to various visual stimuli. A, Responses of vis-I neuron. Solid circles connected by heavy lines indicate mean firing rate in each trial for $5 \mathrm{sec}$ after W1 was opened in 4 repeated trials. Histograms show mean of each $5 \mathrm{sec}$ mean firing rate after the indicated objects were revealed. Broken line indicates spontaneous firing rate. Total of 27 stimuli tested for visual stimuli; only 12 shown here. Stimuli presented in random order; position in sequence of trials among these 12 stimuli shown by number at bottom of each histogram. Order is rearranged here to compare different foods (6 columns at left) with various nonfood objects ( 6 columns at right). $B$, Responses of visII neuron. Note pronounced responses to unfamiliar objects and no response to familiar positive food and neutral object. Order rearranged here to compare different nonfood objects $(6 \mathrm{col}-$ umns at left) with various foods ( 4 columns at right). Total of 25 stimuli tested for visual stimuli; only 10 shown here. Other details as for $A$ except that each response consists of 3 trials.

B

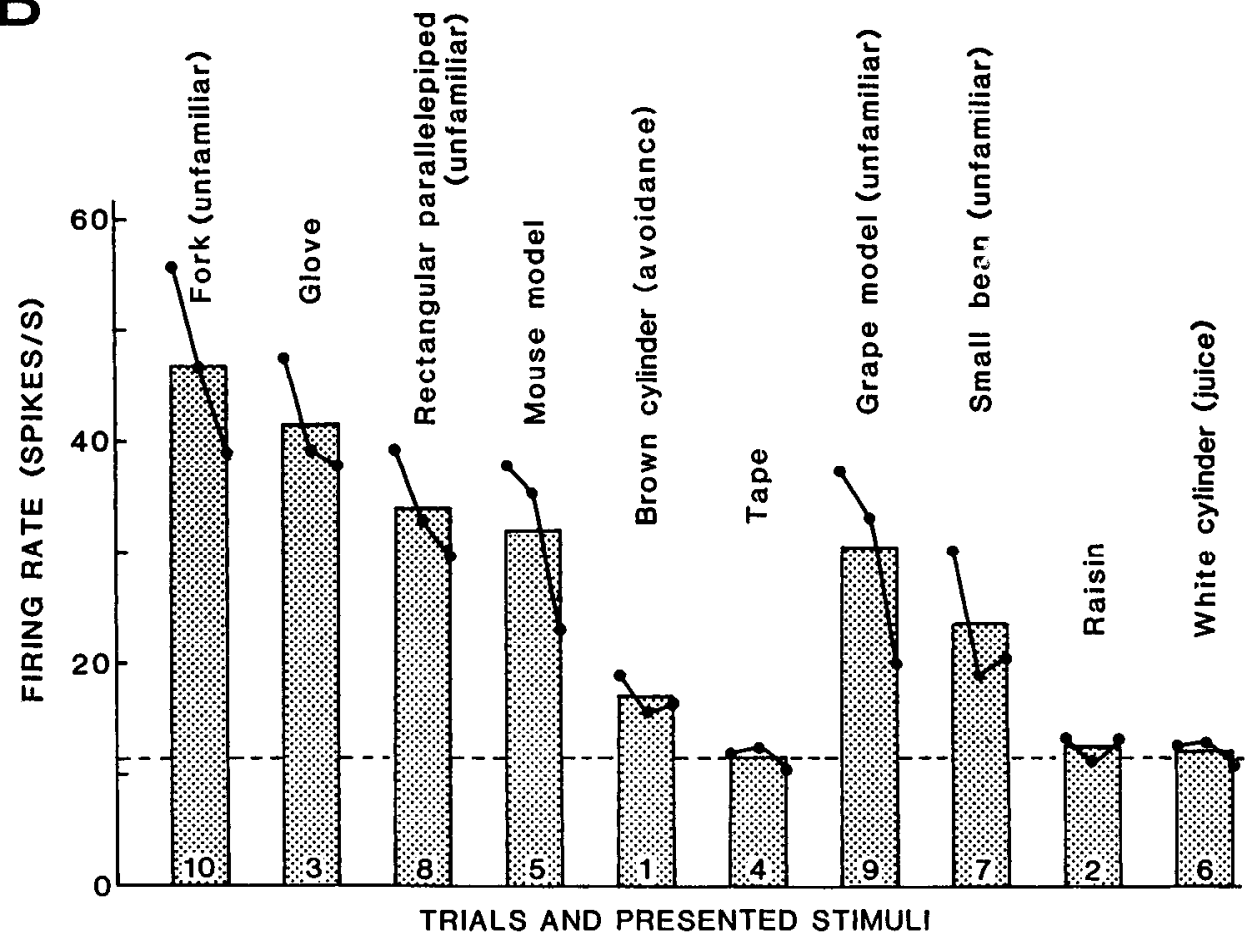

and small bottle), but the response to the small bottle habituated in repeated trials. This neuron also responded consistently to rewarding objects, such as familiar food (orange, potato, jellybean and cookie), a white cylinder associated with juice, and certain familiar aversive nonfood objects (frog model and brown cylinder associated with electric shock). Within these categories of stimuli, it responded more strongly to a preferred food (orange) than to a less preferred food (cookie) (ANOVA, $p<0.01$ ). This neuron responded only slightly or not at all to a roll of tape (familiar, neutral, nonfood) or to the shutter moving but was activated by a familiar wooden rectangular parallelepiped. Although not associated with reward or punishment, this object has some significance for the monkey because in the first 2 presentations the animal pressed the bar and handled it.

Although vis-I neurons responded similarly to both positive and negative stimuli, the change in response that occurred when the affective significance of a stimulus was altered indicates that this factor was more important than the physical characteristics of the stimulus. 'The neuron used as an example in Figure 1 was also studied in a gradually changing situation (Fig. 2). Responses 


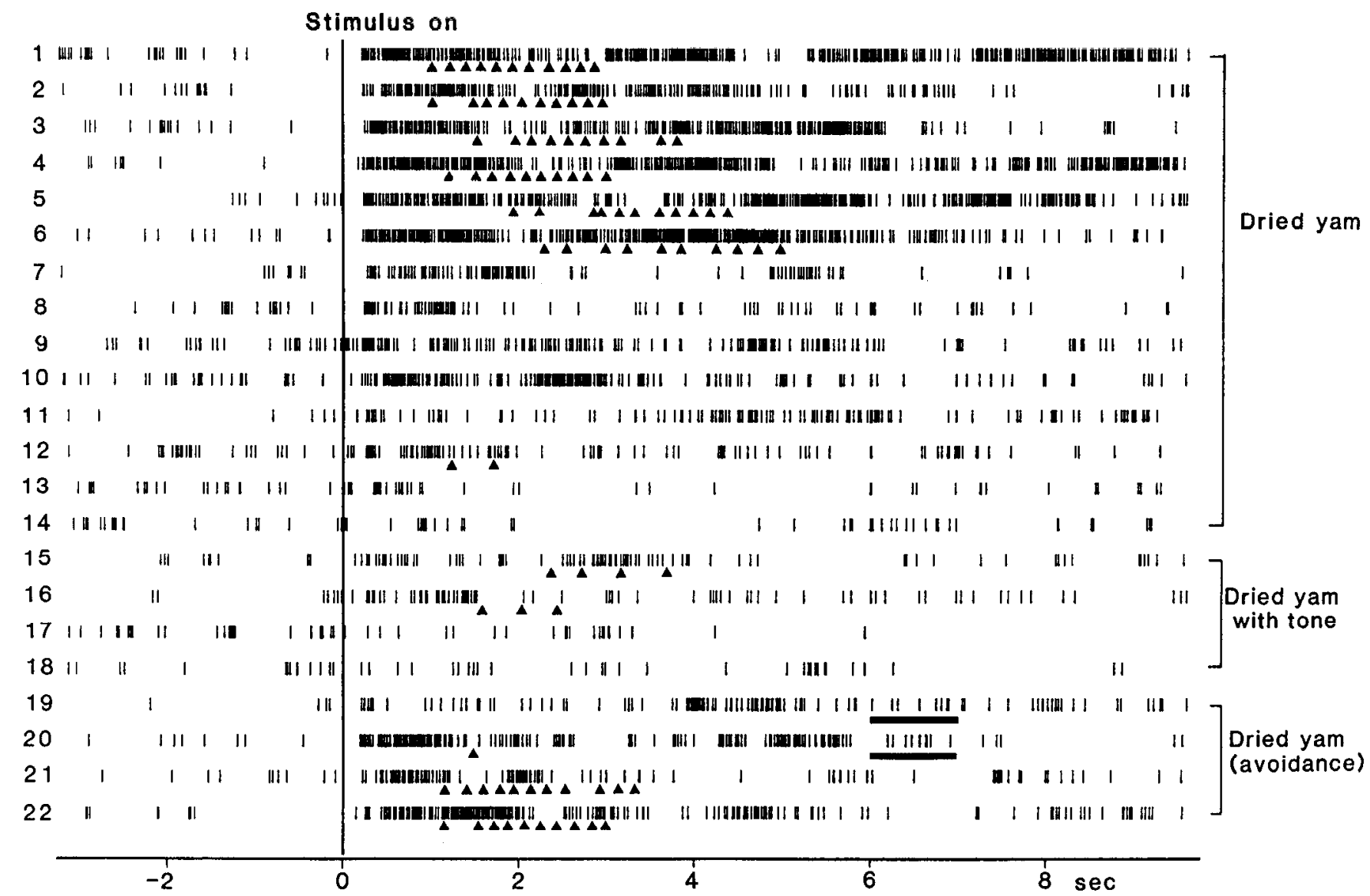

Figure 2. Raster display of responses of neuron exemplified in Figure $1 \mathrm{~A}$. Dried yam, which was handled and smelled but never tasted, was not accepted by monkey as food. In trials 1-14, neuronal and bar pressing responses gradually decreased and finally ceased. In trials $15-18$, dried yam plus a $1200 \mathrm{~Hz}$ tone was presented instead of the brown cylinder plus the $1200 \mathrm{~Hz}$ tone (active avoidance task) without electric shock. In trials 19-22, response appeared again after association with electric shock (heavy underbars in trials 19 and 20). Shock avoided in trials 21 and 22. Abscissa, time (sec); W1 opened at time 0. Each filled triangle below a raster display indicates one bar press.

to an unfamiliar object (dried yam) habituated gradually in trials $1-14$. When the dried yam plus a $1200 \mathrm{~Hz}$ tone was presented instead of the brown cylinder plus the $1200 \mathrm{~Hz}$ tone (avoidance task) without electric shock, the initial response was slight, and it quickly habituated in trials $15-18$. When the dried yam plus the tone preceded electric shock (broad line below raster display in trials 19 and 20), neuronal and bar pressing responses were quickly elicited in trials 19-22. In trial 20 the neuronal response was elicited with only 1 bar press, and in trials $20-22$ the neu- ronal responses were time-locked to presentation of the yam. This observation reveals that the neuronal responses were not related directly to the avoidance situation but to the dried yam associated with electric shock. Thus, the neuronal response to visual stimulation was modified when associated with other stimuli ( $1200 \mathrm{~Hz}$ tone and electric shock) and evinced a relation to overt behavior. The response was not correlated directly to bar pressing because some responses occurred without bar presses in trials 7-10 and some bar pressing occurred without neu-

Table 1. Classification according to affective significance of visual, auditory, and oral sensory stimuli presented

\begin{tabular}{|c|c|c|c|c|}
\hline \multirow[b]{2}{*}{ Stimuli } & \multirow[b]{2}{*}{ Unfamiliar } & \multicolumn{3}{|l|}{ Familiar } \\
\hline & & Positive & Negative & Neutral \\
\hline Visual & $\begin{array}{l}\text { All unfamiliar food, } \\
\text { nonfood, and models of } \\
\text { food }\end{array}$ & $\begin{array}{l}\text { All familiar food, whitc and } \\
\text { red cylinders }\end{array}$ & $\begin{array}{l}\text { Brown cylinder, models of } \\
\text { insects and animals, } \\
\text { syringe, glove }\end{array}$ & $\begin{array}{l}\text { Tape, wooden rectangular } \\
\text { parallelepiped }{ }^{a} \text {, shutter } \\
\text { movement }\end{array}$ \\
\hline Auditory & All unfamiliar sounds & $\begin{array}{l}\text { Buzzer noise, synthesized } \\
\text { tone (fundamental, } 800 \\
\mathrm{~Hz} \text { ) }\end{array}$ & Human voices & $\begin{array}{l}\text { Pure tones ( } 2800 \text { and } 4300 \\
\mathrm{~Hz})\end{array}$ \\
\hline Oral sensory & All unfamiliar real food & $\begin{array}{l}\text { All familiar food, water, } \\
\text { juice }\end{array}$ & Saline, salted food & \\
\hline
\end{tabular}




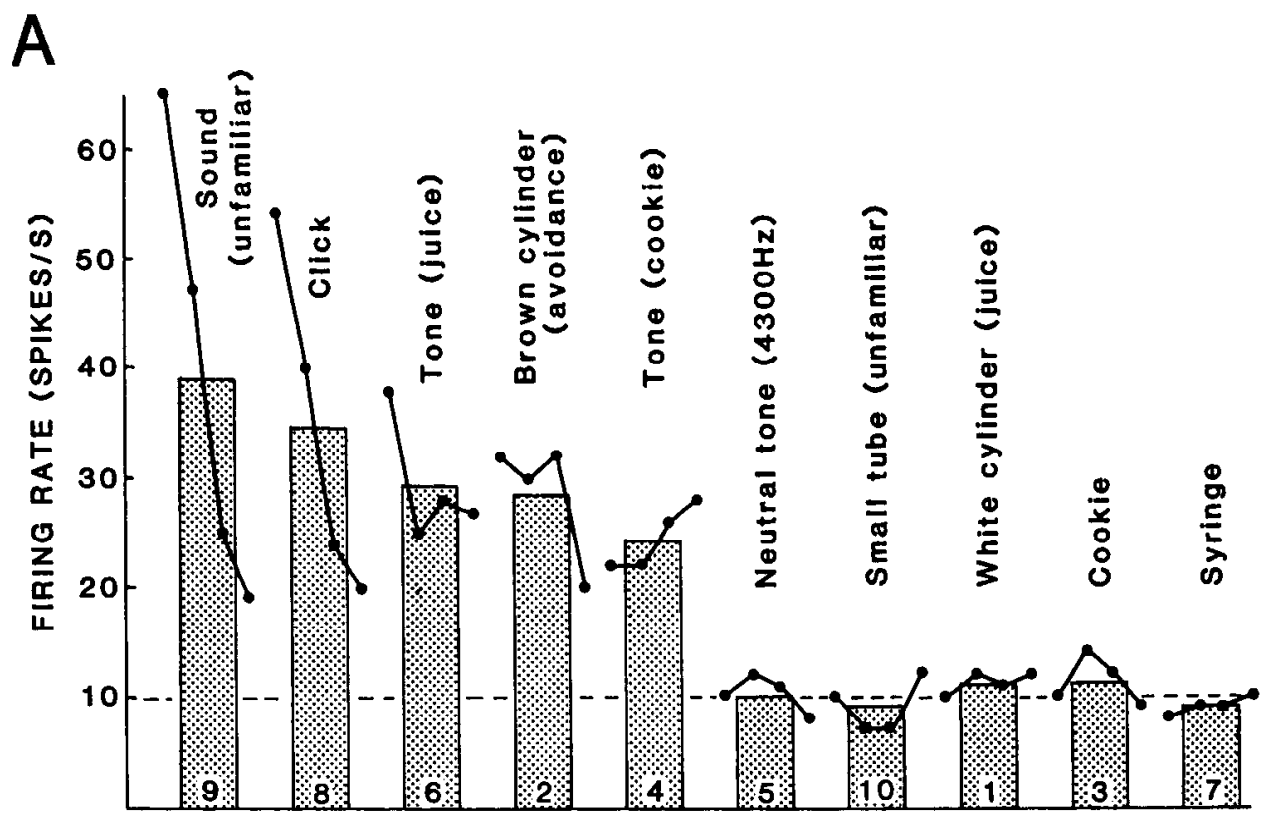

TRIALS AND PRESENTED STIMULI

Figure 3. Comparison of audition-related neuronal responses to various auditory and visual stimuli. $A$, Responses of aud-I neuron. Note consistent responses to familiar tones associated with juice and cookie, and rapid habituation of responses to click and unfamiliar sound. Solid circles connected by heavy lines indicate mean firing rate of each trial for $0.5 \mathrm{sec}$ after tone or sound onset, or W1 was opened in 4 sequential trials. Each histogram shows mean firing rate of 4 trials for $0.5 \mathrm{sec}$. Total of 28 stimuli tested for visual and auditory stimuli; only 10 shown here. Other details as for Figure $1 A$. $B$, Responses of aud-II neuron. Note pronounced responses to unfamiliar sounds and small responses to familiar cue tone associated with juice and to both unfamiliar and familiar visual stimuli. Total of 29 stimuli tested for visual and auditory stimuli; only 10 shown here. Other details as in $A$ (and Fig. 1 $A$ ).
B

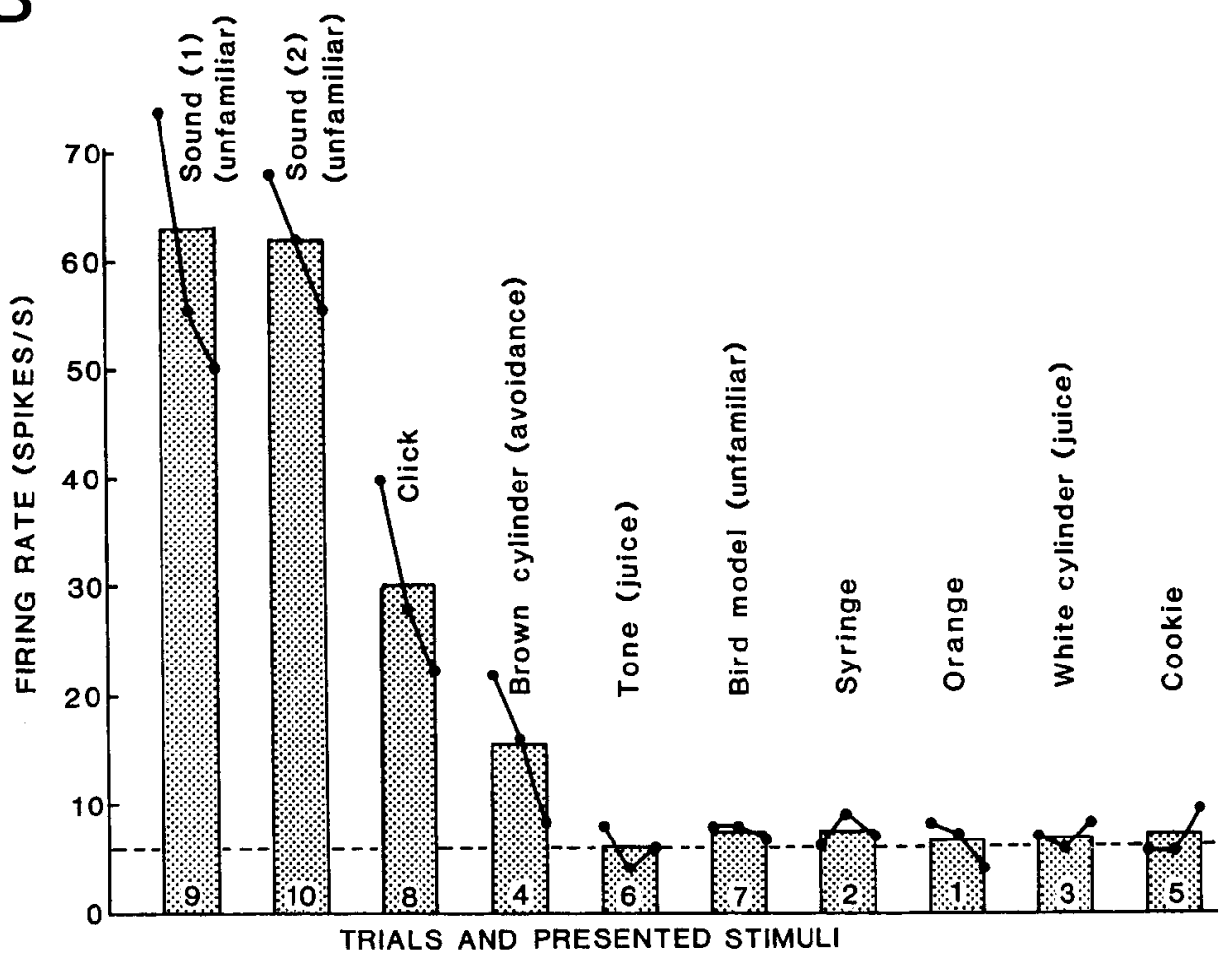

ronal responses in trials 15 and 16 . A similar lack of neuronal and behavioral correlation was evident in other trials (not shown). Of 7 other vis-I neurons tested with other nonfood objects in just the same way, responses of all 7 neurons reappeared when the stimulus was associated with electric shock.

The vis-II neurons are exemplified by the results shown in Figure $1 B$. This particular neuron responded to unfamiliar objects (fork, pink plastic rectangular parallelepiped, grape model, and small bean) and also to certain familiar negative objects (glove, mouse model) but not to familiar neutral nonfood (tape).
The tendency to habituation to unfamiliar stimuli was similar to that of vis-I neurons. This neuron did not respond to familiar reward-related objects (raisin and white cylinder associated with juice), although the animal responded behaviorally to those stimuli.

\section{Audition-related neurons}

There were 26 neurons (4.4\%) that responded exclusively to auditory stimuli (all excited). These neurons were subdivided 


\section{Stimulus on}

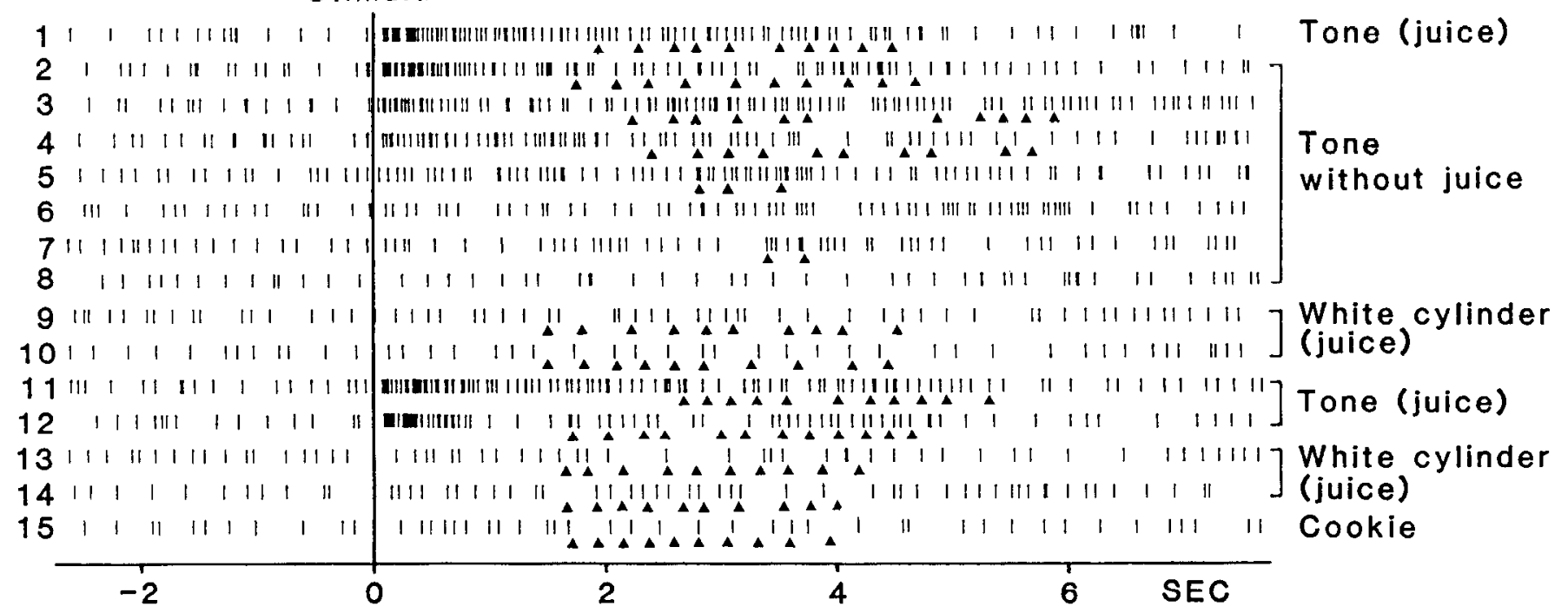

Figure 4. Raster display of aud-I neuron responses during extinction test. Trial 1 is control response to tone associated with juice. In trials $2-8$ the tone was presented without juice reward (extinction). During these trials neuronal and bar pressing responses gradually decreased and finally disappeared. After drinking tasks of trials 9 and 10 the neuronal and bar pressing responses resumed. Other details as in Figure 2.

into 2 groups: those that responded to familiar cue tones associated with a cookie or juice reward, as well as to unfamiliar sounds ( 8 aud-I), and those that responded to unfamiliar sounds but not to cue tones associated with cookie or juice (18 aud-II). Both types responded vigorously to unfamiliar sounds and habituated to certain auditory stimuli in repeated trials; none responded to 2 familiar neutral pure tones $(2800$ and $4300 \mathrm{~Hz}$ ) used as controls.

Figure $3 A$ shows an example of aud-I neuron responses. The responses of audition-related neurons during $0.5 \mathrm{sec}$ after pre- sentation of stimuli were analyzed and compared. The neuron responded consistently to familiar positive auditory cue tones associated with juice and cookie but not to a neutral tone (4300 $\mathrm{Hz}$ ) nor to visual stimuli, including an unfamiliar object (small tube). In contrast to responses to cue tones associated with the juice and cookie, responses to a click and an unfamiliar $80 \mathrm{~dB}$ sound (whistle) habituated.

The responses to cue tones associated with the juice and cookie were not correlated directly to physical properties of the stimuli such as frequency. As with vis-I neurons, responses to cue

\section{W1 open}

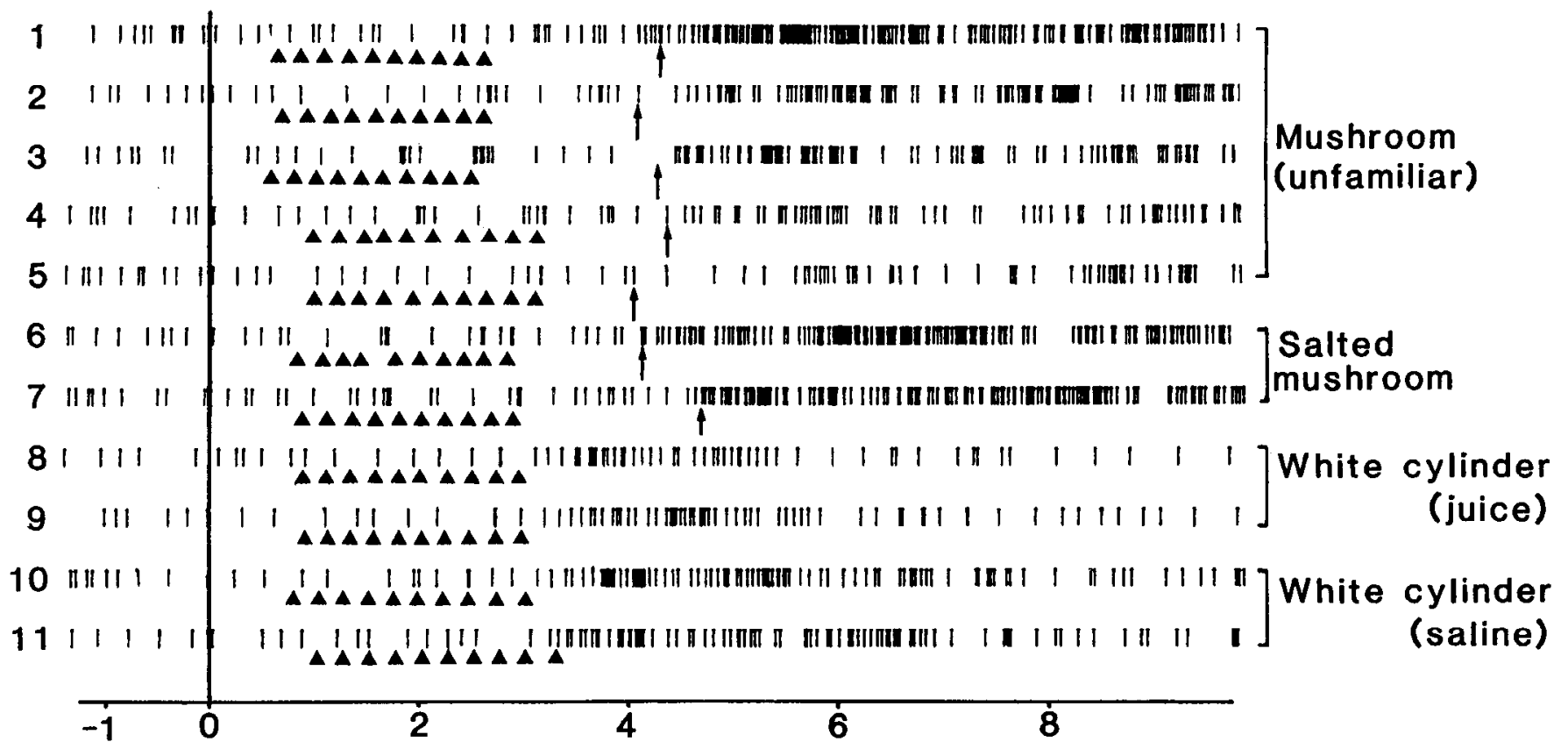

Figure 5. Raster display of oral sensory neuron responses in sequential food, salted food, and saline trials. Note habituation of responses to mushroom in trials 1-5. After habituation, salting mushroom elicited responses again in trials 6 and 7 . In trials 10 and 11 neuron responded to saline that was provided in lieu of juice in drinking task. Other details as in Figure 2. 


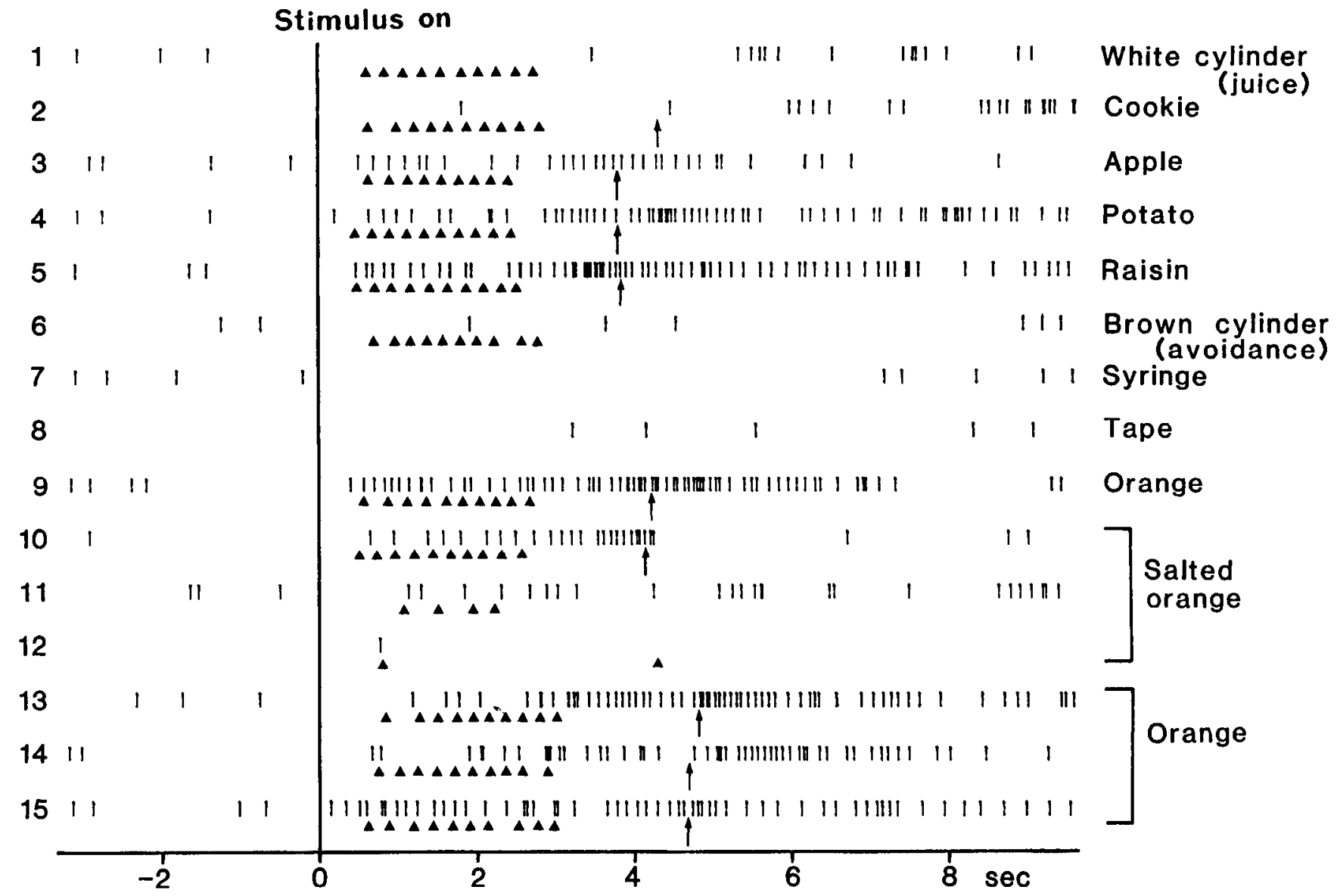

Figure 6. Raster display of oral sensory plus vision neuron responses. Neuron responded slightly to the ingestion of juice and cookie in trials 1 and 2 . Activity increased primarily in and immediately preceding ingestion phase in trial 3-5. Note no neuronal response in bar press phase in avoidance task (trial 6). Trials 9-15 show reversal associated with salted food. Note that neuronal response disappeared at the moment when animal put a salted orange into its mouth (arrow in trial 10). Other details as in Figure 2.

tones were associated with the affective significance of the stimuli because, in the 4 neurons tested, the response diminished during extinction (Fig. 4). In trials $2-8$ a cue tone (fundamental, $800 \mathrm{~Hz}$ ) was presented without a juice reward. The neuronal responses gradually decreased and finally disappeared during these trials. After an intervening drinking task of trials 9 and 10 , neuronal and bar pressing responses resumed in trials 11 and 12. Although the latency of bar pressing response in the first trial after the drinking task (trial 11) was longer than those in trials $1,9,10$, and 12-15, the latency also resumed in the next trial (trial 12). Note that the same juice reward associated with a visual cue (white cylinder) elicited a behavioral response but no increase in neural activity.

The 18 aud-II neurons responded vigorously to unfamiliar sounds but not to familiar cue tones associated with food or juice. Figure $3 B$ shows an example of aud-II neuron responses. This neuron responded vigorously to 2 unfamiliar complex sounds-one made when the experimenter dropped a wrench on the floor (sound 1) and another made when the experimenter hit a plastic bottle with a stick out of the animal's visual field (sound 2)-but not to a familiar tone associated with juice or to visual stimuli, including unfamiliar objects (bird model). The peak intensity of sounds 1 and 2 in each trial ranged from 80 to $85 \mathrm{~dB}$. The aud-II neurons typically habituated to clicks within 2 or 3 trials (Fig. $3 B$ ).

\section{Ingestion-related neurons}

There were 41 neurons $(7.0 \%)$ that responded primarily during the ingestion phase of the discrimination tasks. Based upon the analysis presented in the preceding paper, this group was subdivided into 3 groups: 27 oral sensory, 11 oral sensory plus vision, and 3 oral sensory plus audition.

The first characteristic of oral sensory neurons was a greater responsiveness to both preferred and unfamiliar foods than to familiar, less preferred foods (described in the preceding paper). Most of the oral sensory neurons, however, also responded to negative oral stimuli. Of the 27 oral sensory neurons, 9 were tested with saline or salted food, and 8 of these responded to these aversive oral sensory stimuli as they did to normal food or juice. The response of only 1 neuron was attenuated by salted food. This exceptional neuron responded only to raisins and oranges, but not to other foods. The other 26 neurons responded to a wide variety of foods, although the magnitude and latency of the responses differed depending on the particular food being ingested. The responses of a typical oral sensory neuron are shown in the raster display of Figure 5. Although bar pressing and mouth movement did not change, neuronal responses to mushroom habituated in successive trials $1-5$. The responses reappeared when a salted mushroom was used in trials 6 and 7. In trials 8 and 9 the neuron responded to ingestion of a juice 


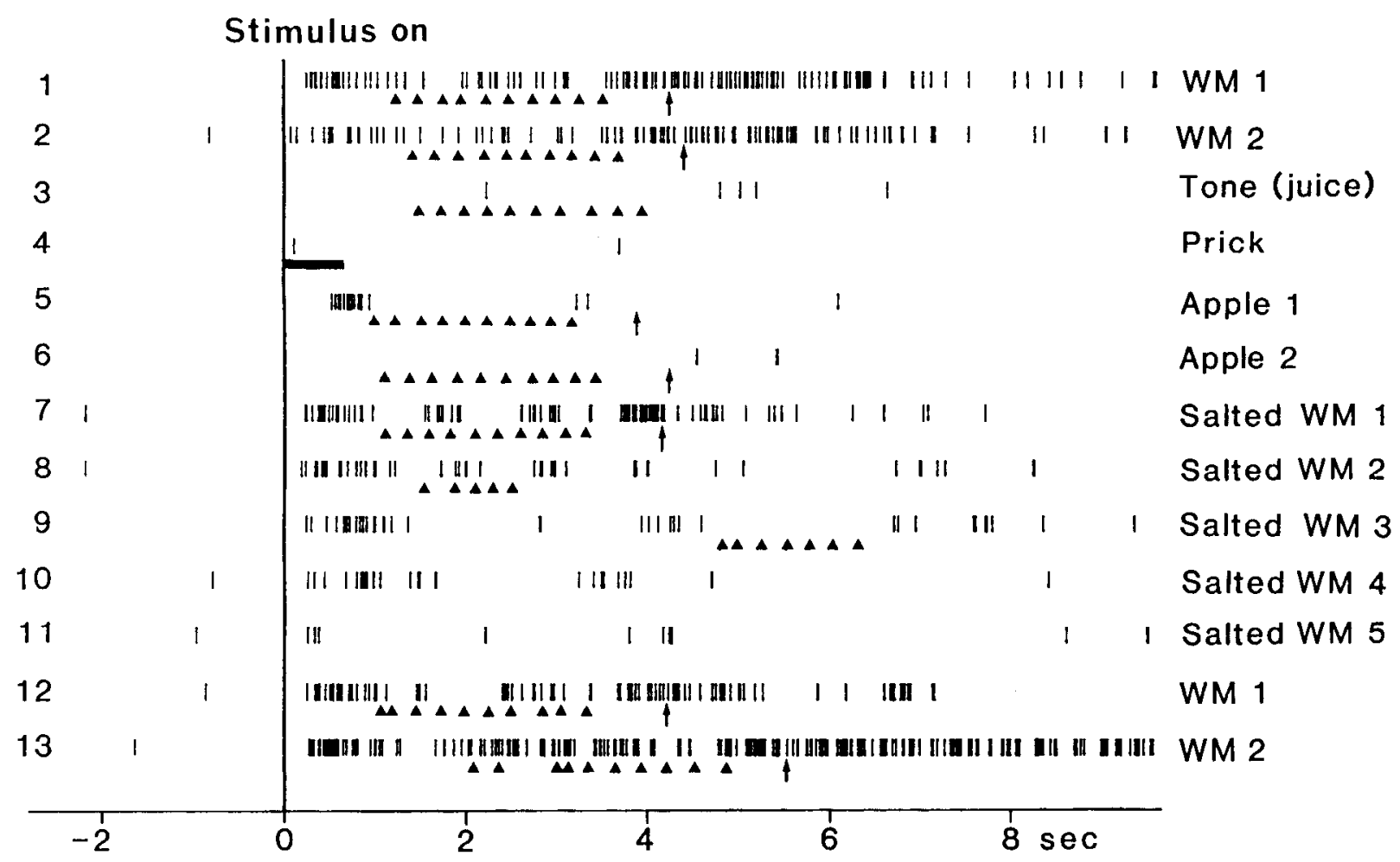

Figure 7. Raster display of responses of neuron selective to watermelon to various stimuli and modulation of responses to watermelon by salting. Neuron responded to sight and ingestion of normal watermelon in trials 1 and 2 but not to tone associated with juice in trial 3 and somesthetic stimulation (prick) in trial 4. In trials 5 and 6, responses to apple habituated in only one trial. Note that neuronal response decreased the moment when the animal put salted watermelon into its mouth (arrow in trial 7). In trials 8-11 the neuronal and bar pressing responses gradually decreased and finally disappeared. Other details as in Figure 2.

reward. This neuron also responded to saline presented in lieu of the juice that was normally predicted by a white cylinder (trials 10 and 11). This neuron also responded to forcibly ingested saline (not shown).

The 11 oral sensory plus vision neurons responded to both sight and ingestion of some, but not all, food stimuli. In contrast to the pure oral sensory neurons, salted food attenuated the activity of the 4 oral sensory plus vision neurons that were tested. The responses of such a neuron are documented in the raster displays of Figure 6 . The neuron may have responded slightly in the late ingestion phase to a white cylinder associated with juice and to a cookie in trials 1 and 2 . In the visual and ingestion phases, this neuron responded to apple, potato, raisin, and orange in trials 3-5, 9, and 13-15. The response differences to the various food stimuli showed no correlation with mouth movement and neuronal activity. In addition, in our feeding paradigm, mouth movement was slight or absent during the discrimination and bar press phases. This suggests that the neuronal responses preceding ingestion were not preparatory to mouth movement. Similarly, bar pressing behavior did not correlate with neuronal activity in trials 6,13 , and 14, but visual presentation of a normally ingested food did elicit activity in trials 9 and 15. The neuron represented in Figure 6 did not respond to any known aversive or neutral objects, such as the brown cylinder that was associated with electric shock, a syringe, tape, or salted orange (trials $6-8,12$, and others, not shown). Trials 9-15 show the effects of salting food. The attenuation was apparent during both the visual inspection and ingestion phases of the task. In the first salted food trial (trial 10), the response disappeared immediately after putting salted orange into the animal's mouth. Salting of food was always done in such a way that the salt could not be seen, so it was first detected by the animal upon ingestion. The response to the sight of orange diminished in subsequent salted food trials (trials 11 and 12), as well as in the first 2 unsalted food trials that followed (trials 13 and 14). After the experimenter gave a piece of unsalted orange to the animal by hand, bar pressing to obtain orange began again in trials 13 to 15 , and neuronal responses to the sight and ingestion of orange quickly recovered.

\section{Multimodal neurons}

There were 40 multimodal phasic (36 excited, 4 inhibited) and 77 multimodal tonic (69 excited, 8 inhibited) neurons. The responses of multimodal phasic neurons occurred regardless of their affective significance (positive, negative, or neutral). Multimodal tonic neurons, on the other hand, responded to the affective significance of stimuli in a manner similar to that of vis-I and aud-I neurons. Briefly, they responded to both reward stimuli (food, red or white cylinder associated with water or juice, auditory cues associated with juice or food) and potentially aversive stimuli (brown cylinder associated with electric shock, glove, syringe, white mouse model, etc.) but only slightly or not at all to familiar neutral stimuli.

\section{Selective neurons}

There were 14 neurons $(2.4 \%)$ that responded only to a single specific stimulus item. Of the 6 neurons that responded to a specific food stimulus, 4 were tested by salting the food that elicited activity. Salting reversibly attenuated their selective responses after a few trials. One neuron that responded only to 


\section{A. EOG}

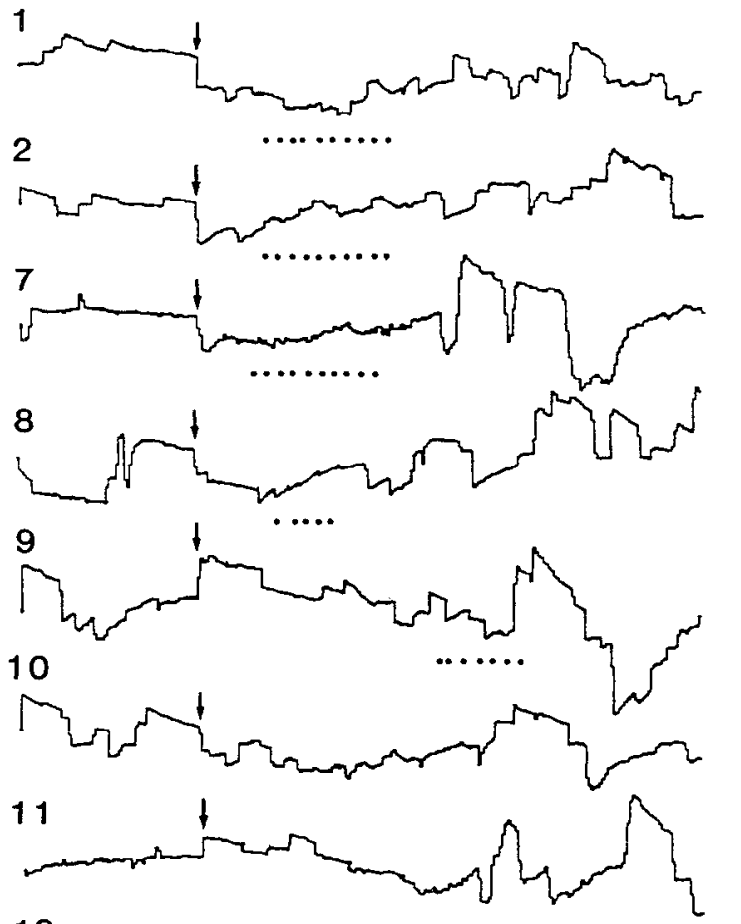

12

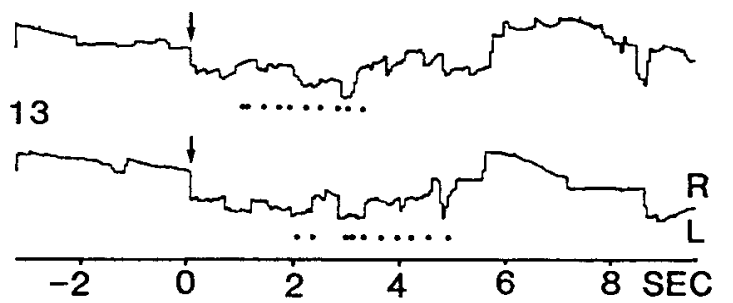

B. FIRING RATE

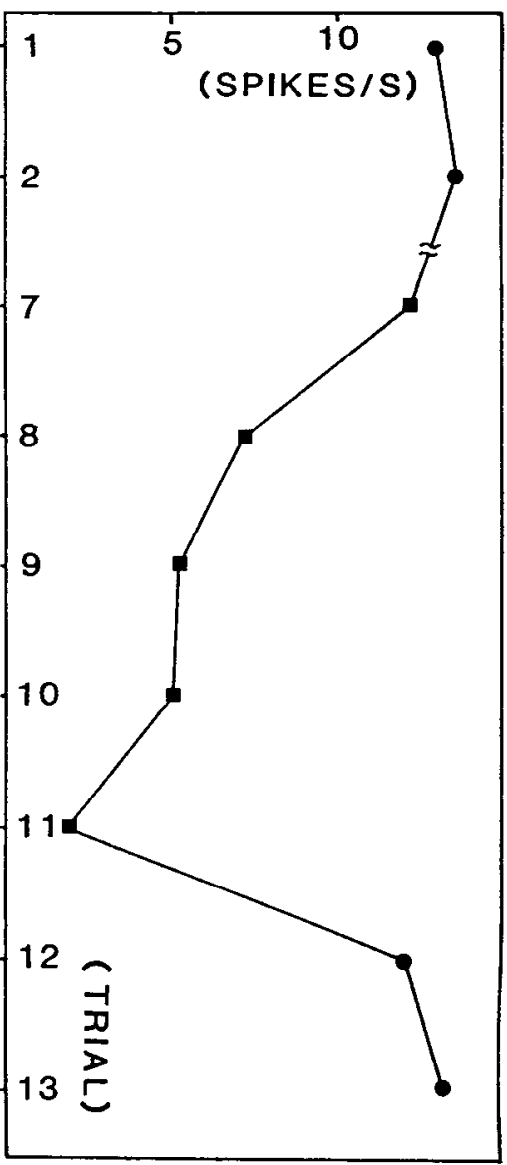

Figure 8. Electrooculograms (EOG, $A$ ) and neuronal responses to sight of watermelon $(B)$ in normal and salted trials shown in Figure 7. $A$, EOG, upward deflection, movement to right $(R)$; downward deflection, movement to left (L). Arrows, time of W1 opening. $A b-$ scissa, time (sec); W1 opened at time 0 . Each dot below EOG represents one bar press. $B$, solid symbols connected by heavy lines indicate mean firing rate for $5 \mathrm{sec}$ after W1 opening. Note absence of neuronal responses in trial 11 despite EOG change after W1 opening. Solid circles, unsalted trials; solid squares, salted trials. Numbers at left of $A$ and $B$ correspond to trial numbers in Figure 7 . the white cylinder associated with juice was tested for extinction, and 48 trials were necessary to extinguish the neuronal and behavioral response.

The modulation of activity of a neuron that selectively responded to watermelon is shown in Figure 7 . The neuron responded consistently at the sight and ingestion of watermelon in trials 1 and 2 but did not respond to the rewarding cue tone associated with juice and its ingestion in trial 3 nor to a presumably aversive somesthetic stimuli (prick) in trial 4 . The neuron responded slightly at the sight of an apple only in the first trial with this stimulus (trial 5). In trials 7-11, salted watermelon reversibly modified the activity that occurred during both the sight and ingestion of that stimulus. Salted watermelon was visually indistinguishable from unsalted watermelon, and in trial 7 the neuron responded as previously until the salted watermelon was ingested (indicated by arrow), at which point, the activity suddenly decreased. In trials 8-11 the response to the sight of watermelon gradually decreased and finally disappeared. After the experimenter gave a piece of unsalted watermelon to the animal, neuronal and bar pressing responses resumed in trials 12 and 13 . Figure 8 shows specimen records of EOG and neuronal responses of this monkey during the normal and salted-food trials shown in Figure 7. Comparison of the $\mathrm{EOG}$ in the first $5 \mathrm{sec}$ of each trial shows no correlation with neuronal activity during the same period (Fig. $8, A, B$ ).

\section{Location of each type neurons}

The distributions of the various type neurons are illustrated in Figure 9. The neurons in Figure 9 are the same neurons illustrated in Figure 10 in the preceding paper. Vis-II neurons tended to be located in the anterior dorsolateral part of the AM, including the lateral nucleus ( $A$, open triangles). Vis-I neurons were more medial than vis-II, that is, in the border area between the basolateral nucleus and the other nuclei ( $A$, open circles). The aud-II neurons were located in the posterolateral part of the AM (mainly in the lateral nucleus and its border with the hasolateral nuclei) and in the border zone between the basomedial nucleus and the corticomedial group ( $B$, open triangles). The aud-I neurons were located in the posterior basolateral nucleus ( $B$, open circles). Oral sensory neurons were located in the corticomedial group and the medial part of the lateral nucleus or along the border between the lateral and basolateral nuclei ( $C$, open circles). Most of the oral sensory plus vision neurons were along the dorsal surface of the basolateral nucleus, and one was in the border area between the putamen and the corticomedial group ( $C$, open squares). The oral sensory plus audition neurons were on the posterior dorsal surface of the basolateral nucleus ( $C$, open triangles). The excitatory multimodal tonic neurons were widely distributed in the AM except for the lateral part ( $D$, open squares). The inhibitory multimodal 
A. VISION (VIS) (0:VIS-I, $\triangle:$ VIS-II)
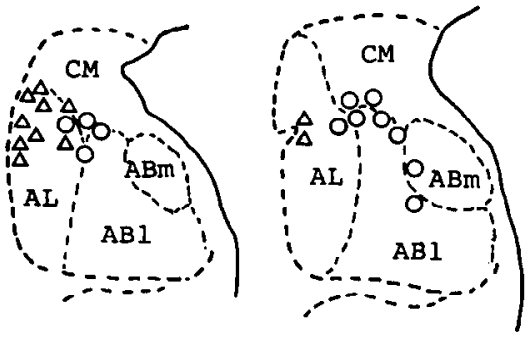

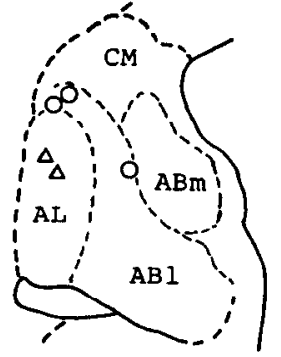

\section{E:EXCITATION, I:INHIBITION}
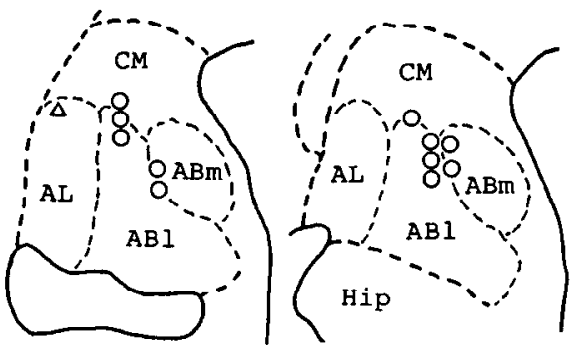

B. AUDITION (AUD) (0:AUD-I, $\triangle:$ AUD-II)
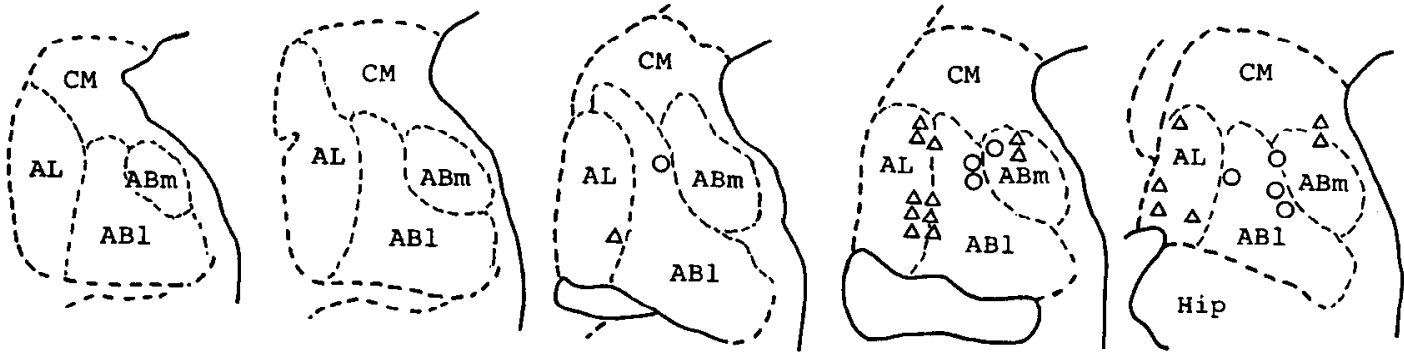

\section{INGESTION (ORL)}
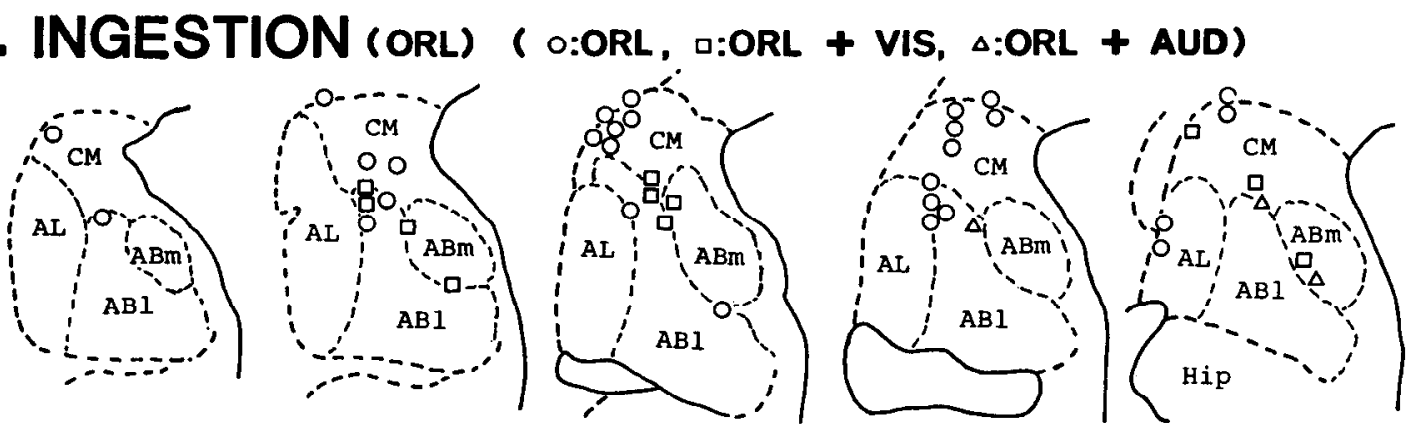

D.MULTIMODAL TONIC ( $\left(::_{,}\right.$, : : 1 ) / SELECTIVE ( $)$
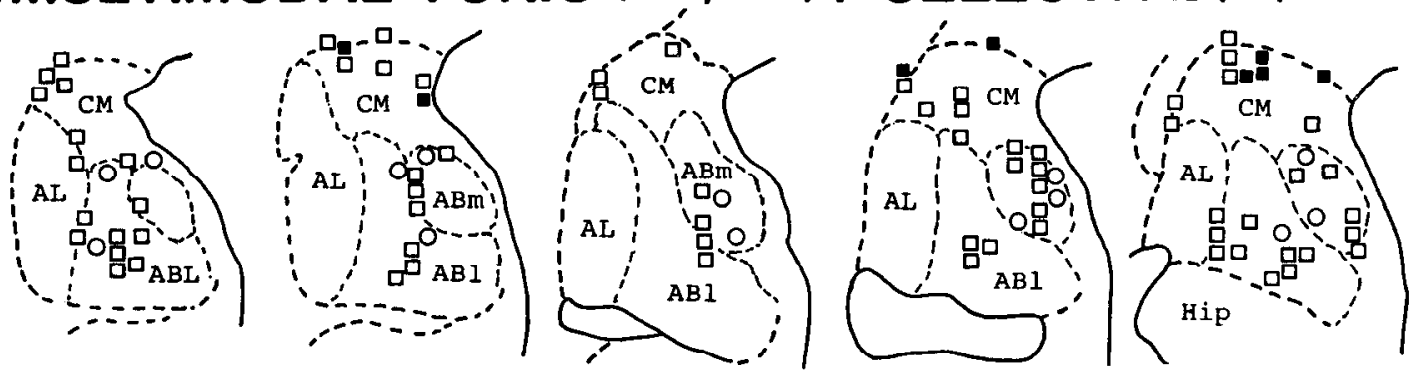

\section{E. MULTIMODAL PHASIC $(0: E,-:: 1)$}

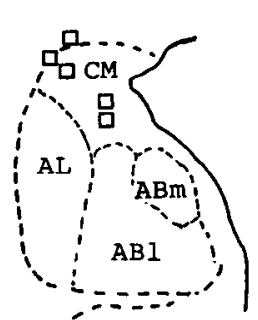

A22

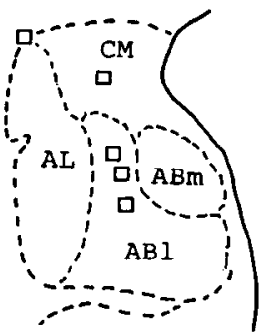

A21

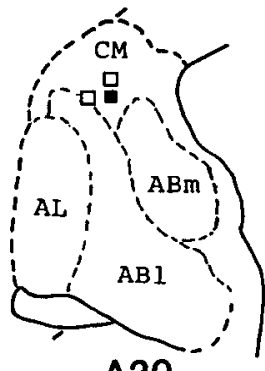

A20

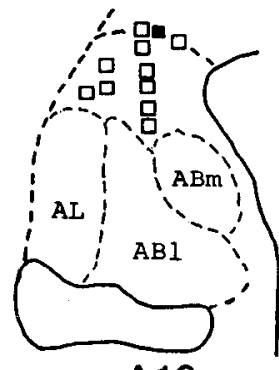

A19

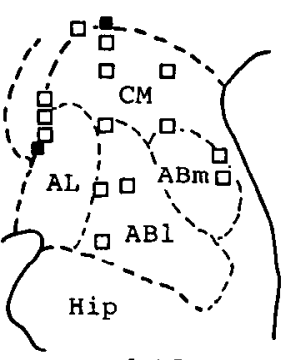

A18

Figure 9. Recording sites of 5 major neuron types. A, Vision related; open circles, vis-I; open triangles, vis-II. B, Audition related; open circles, aud-I; open triangles, aud-II. $C$, Ingestion related; open circles, oral sensory $(O R L)$; open squares, oral sensory plus vision $(O R L+V I S)$; open triangles, oral sensory plus audition $(O R L+A U D) . D$, Multimodal tonic or selective; open (excitatory) and filled (inhibitory) squares, multimodal tonic; open circles, selective. $E$, Multimodal phasic. Open symbols, excitatory; filled symbols, inhibitory responses. CM, corticomedial group of amygdala; $A L$, lateral nucleus; $A B l$, basolateral nucleus; $A B m$, basomedial nucleus. Numbers below each section indicate distance (mm) anterior from interaural line. 
tonic neurons were located only in the dorsal part of the corticomedial group ( $D$, filled squares). The selective neurons were located in the basolateral and basomedial nuclei $(D$, open circles). The distribution of the multimodal phasic type neurons ( $E$, open and filled squares) as similar to that of the multimodal tonic neurons.

\section{Discussion}

We have described 5 broad categories of AM neuronal responses. Within the vision-related, audition-related, or multimodal categories, none of the neurons responded selectively to positive or negative stimuli. Most of oral sensory neurons also responded to both positive and negative oral sensory stimuli. These neurons were functionally recategorized into one group (nonspecific neurons). On the other hand, the response of some oral sensory plus vision neurons and some stimulus-specific neurons was modulated by altering the affective significance of the stimuli (differential neurons).

\section{Nonspecific neuron responses}

These neurons (vis-I, aud-I, multimodal tonic types; $n=111$ ) responded to both positive and negative stimuli but not to familiar neutral stimuli. The responses of most oral sensory neurons were similar to those of the 111 neurons. Previous studies have reported neurons in the dorsolateral AM that respond similarly to visual stimuli associated with both reward and aversion (Sanghera et al., 1979; Ono et al., 1983). Those neuronal responses were easily modulated by extinction or by changing the affective significance of the stimuli (Figs. 2 and 4), suggesting that, even though vis-I and aud-I neurons were modality specific, they responded more to the affective significance of the stimuli than to their physical characteristics. These neurons might function to differentiate stimuli that are important to the animal from those that are not, regardless of the nature of the significance. This function may be involved in processes related to attention, reflected by the animal's concentration on a specific stimulus among various exteroceptive stimuli. Because of difficulty in obtaining an independent measure of attention, our data cannot substantiate this suggestion. Nevertheless, the idea is compatible with the observation that some vis-I and aud-I neurons responded to unfamiliar objects or sounds but soon habituated to those stimuli that were not paired with reward or aversion (Figs. 1-3). Similar habituating responses in the AM neurons have been reported by Ono et al. (1980). Gross et al. (1979) reported a similar type of neuron in the inferotemporal cortex, and they suggested a relation between those neurons and eye fixation or attention. The neurons in the present and previous (Gross et al., 1979) studies, however, did not change their firing levels when the animals spontaneously looked away from the test apparatus.

In 32 neurons (vis-II, aud-II), only unfamiliar and certain familiar negative nonfood or sound stimuli elicited preferential responses. This characteristic differentiated these neurons from neurons that also responded to familiar visual or auditory stimuli associated with reward (vis-I, aud-I). Most of these 32 neurons also habituated as stimuli became familiar, although habituation to certain aversive nonfood items was slow or absent. Sawa and Delgado (1963) reported AM neurons that habituated rapidly to clicks but not to the meow of a cat. In the present experiments, this type of neuron (vis-II, aud-II) was located primarily in the lateral part of the AM. We previously reported neurons similar to the vis-II neurons that had relatively pref- erential responses to ccrtain familiar aversive nonfood objects and were located in the anterolateral AM (Ono et al., 1983). Since electrical stimulation in the lateral AM elicited orienting and flight responses (Kaada, 1972), these neurons might be related to such reactions.

The responses of 40 neurons were independent of the nature of the stimuli, and these responses tended to be phasic (multimodal phasic neuron). This suggests that these neurons might be related to arousal. Anatomically, it has been reported that the AM receives afferents from nonspecific nuclei of the thalamus. The activity of these afferents is believed to be associated with arousal and pain (Aggleton et al., 1980).

Some of the neurons that responded to various stimuli could be involved in arousal, attention, or orientation. Stimulation of the AM produced arousal reactions such as orientation responses and EEG desynchronization (Goddard, 1964; Kaada, 1972; Isaacson, 1982). $\Lambda \mathrm{M}$ lesions caused deficits in orienting (Bagshaw et al., 1972) and decreased attention to a task (Masserman et al., 1958). Attention or orienting reactions are thought to be part of the sensory perception necessary for object recognition (Geschwind, 1982). It has been reported that animals with AM lesions are less responsive than controls to both rewarding and aversive stimuli (Weiskrantz, 1956; Nachman and Ashe, 1974). It was concluded that the lesioned animals had general perceptual deficits in their ability to recognize the significance of stimuli, whether rewarding or punishing, due to altered perceptual processes involved in alerting and attention (Nachman and Ashe, 1974). On the other hand, stimulation of the AM was reported to produce profound heart rate and blood pressure changes (Kapp et al., 1982; Applegate et al., 1983), and lesion of the AM attenuated conditioned heart rate changes during Pavlovian fear conditioning (Kapp et al., 1979). Nonspecific neurons in the present study might also contribute to autonomic changes when the animal encounters emotionally effective items.

\section{Differential neuron responses to affective significance}

The responses of 4 oral sensory plus vision and 4 selective neurons were suppressed by alteration of affective significance. Because the food was carefully salted to avoid changing its appearance, the attenuation of responses was not due to differences in presentation. Nevertheless, the suppression of neuronal activity associated with salted food might have been due to some change in behavior, such as diverted attention. This is unlikely, however, because we monitored adjunctive behavior in 3 different ways, including the animal's gaze (see Materials and Methods). Two monkeys continued to press the bar even after experiencing salted food, but they struck the food off the turntable instead of eating it. In these cases, neuronal activity remained suppressed. The responses of oral sensory plus vision neurons to unsalted and salted oranges (Fig. 6), although not specific, were the same as the specific responses to watermelon (Fig. 7). The responses of both type of neurons were first suppressed during the initial ingestion of salted food, then suppression of visual responses followed. That is, alteration of oral sensory stimuli (salting food) resulted in suppression of visual responses, which suggests relations of these neurons to visualoral sensory (gustatory) association. Geschwind (1965) suggested a role for limbic system in visual-gustatory association, which is essential for stimulus-reinforcement association. Diverted attention is insufficient to explain suppression of the ingestion responses. In preliminary experiments, we observed suppression 
of gustatory responses by quinine (unpublished observations) that was similar to the present finding of suppression by salt. This suggests that the suppression was not taste specific but was due to some other quality, possibly aversion. Although alternative sensory characteristics may have contributed, we suggest that our present results, along with previous findings (Nishijo et al., 1986), indicate that reward or aversion contributes to at least some of the neuronal responses observed.

Sanghera et al. (1979) suggested that AM neurons responded partially to the significance (rewarding or aversive) and partly to the physical properties of a stimulus. They minimized the modulatory effect that changing the affective significance of a stimulus had on neuronal responses. Our results agree with the first part of this conclusion. Neurons that responded uniquely, i.e., to the sight of a single or a few specific stimuli (raisins, watermelon, cylinders), did not depend absolutely on their physical properties, but rather on some abstract aspect(s) of the stimuli. The neuron that responded selectively to watermelon, for instance, responded to different shapes of the watermelon pieces but not to a strawberry model, which was also red, nor to the red cylinder associated with water. Unlike the results of Sanghera et al. (1979), however, salting the food attenuated the response of this neuron. The lack of selective and oral sensory plus vision neurons in the earlier study might have been due, in part, to their more restricted recording sites, which were located mainly in anterodorsal AM.

The inferotemporal cortex of primates is involved in higher visual information processing. Animals with lesions of the inferotemporal cortex have deficits in initial learning or relearning of discrimination of objects or 2-dimensional patterns (Iwai and Mishkin, 1969; Dean and Weiskrantz, 1974; Weiskrantz and Saunders, 1984). Some inferotemporal cortex neurons respond to only one pattern regardless of size or color (Gross et al., 1969, 1972; Sato et al., 1980; Desimone et al., 1984) or to specific colors (Fuster and Jervey, 1982; Desimone et al., 1984). These studies suggest that the inferotemporal cortex is critical for storing "prototypes" of visual objects (Weiskrantz and Saunders, 1984). Since the AM receives massive afferent projections from the inferotemporal cortex (Herzog and Van Hoesen, 1976; Aggleton et al., 1980; Turner et al., 1980; Iwai and Yukie, 1987), the existence of neurons that respond uniquely to one or a few significant objects suggests the possibility of association, in the AM, of visual prototypes with reward or punishment associations. These neurons might be related to the association of not all, but of certain visual affective prototypes. The function of these neurons seems to be related to associative memory by which the animal discriminates positive from negative objects. Therefore, we suggest that the AM might be the first stage of stimulus-affective association, since neuronal activity in the inferotemporal cortex was not modulated by the association of visual stimuli with affective significance (Rolls et al., 1977). This suggestion is consistent with lesion studies. In monkey, lesions of AM alone or combined with hippocampal damage produce deficits in an object-reward association task (Spiegler and Mishkin, 1981; Zola-Morgan and Squire, 1984) and in discrimination of food from nonfood (Iwai et al., 1986). In rats, similar AM lesions produced deficits in conditioned taste aversion (Nachman and Ashe, 1974; Fitzgerald and Burton, 1981; Yamamoto et al., 1981). These particular neurons might also be related to rccall of cmotionally significant stimuli. Electrical stimulation in the human AM elicited hallucination or experiential phenomena, some of which were related to personal history and previous events (Halgren et al., 1978; Gloor et al., 1982; Sarter and Markowitsch, 1985).

\section{General discussion}

Both anatomical and physiological evidence has revealed massive connections between the inferotemporal cortex and the AM (Herzog and Van Hoesen, 1976; Aggleton et al., 1980; Turner et al., 1980; Iwai and Yukie, 1987) and between the AM and the hypothalamus (Nauta, 1961; Krettek and Price, 1978; Amaral et al., 1982; Ono et al., 1985). Based upon the fact that response latency to visual stimuli increases from the inferotemporal cortex to the hypothalamus, Rolls (1981) suggested that visual information is processed sequentially from the inferotemporal cortex to the AM and from the AM to the hypothalamus. Previously, we demonstrated that cooling of inferotemporal cortex modulated AM visual responses and that AM cooling modulated the visual and gustatory responses of the lateral hypothalamic neurons (Fukuda et al., 1987). Neurons in the inferotemporal cortex respond selectively to specific objects (Gross et al., 1969, 1972; Sato et al., 1980; Desimone et al., 1984 ) and appear to be involved in the analysis of visible physical properties (Rolls et al., 1977; Desimone et al., 1984; Weiskrantz and Saunders, 1984). Thus, the AM might function to associate the neuronal activity elicited by specific stimuli in selective neurons of the inferotemporal cortex with the affective significance attached to that stimulus. Selective neurons in the $\mathrm{AM}$, in turn, then converge on lateral hypothalamic neurons that respond to any kind of food and to reward-associated objects (Fukuda et al., 1986; Ono et al., 1986). This flow of information from inferotemporal cortex through AM to lateral hypothalamic area might be important in associative learning when the animal must associate visual stimuli with reward or aversion (Rolls, 1981; Fukuda et al., 1987).

\section{References}

Aggleton, J. P., M. J. Burton, and R. E. Passingham (1980) Cortical and subcortical afferents to the amygdala of the rhesus monkey ( $\mathrm{Ma}$ caca mulatta). Brain Res. 190: 347-368.

Amaral, D. G., R. B. Veazey, and W. M. Cowan (1982) Some observations on hypothalamo-amygdaloid connections in the monkey. Brain Res. 252: 13-27.

Applegate, C. D., B. S. Kapp, M. D. Underwood, and C. L. McNall (1983) Autonomic and somatomotor effects of amygdala central $\mathrm{N}$. stimulation in awake rabbits. Physiol. Behav. 31: 353-360.

Bagshaw, M. H., N. H. Mackworth, and K. H. Pribram (1972) The effect of resections of the inferotemporal cortex or the amygdala on visual orienting and habituation. Neuropsychologia 10:153-162.

Chapman, W. P., H. R. Schroeder, G. Geyer, M. A. B. Brazier, C. Fager, J. L. Poppen, H. C. Solomon, and P. I. Yakovlev (1954) Physiological evidence concerning importance of the amygdaloid nuclear region in the integration of circulatory function and emotion in man. Science 120: 949-950.

Dean, P., and L. Weiskrantz (1974) Loss of preoperative habits in rhesus monkeys with inferotemporal lesions: Recognition failure or relearning deficit? Neuropsychologia 12: 299-311.

Desimone, R., T. D. Albright, C. G. Gross, and C. Bruce (1984) Stimulus-selective properties of inferior temporal neurons in the macaque. J. Neurosci. 4: 2051-2062.

Fitzgerald, R. E., and M. J. Burton (1981) Effects of small basolateral amygdala lesions on ingestion in the rat. Physiol. Behav. 27: 431437.

Fukuda, M., T. Ono, H. Nishino, and K. Sasaki (1986) Visual responses related to food discrimination in monkey lateral hypothalamus during operant feeding behavior. Brain Res. 374: 249-259.

Fukuda, M., T. Ono, and K. Nakamura (1987) Functional relations among inferotemporal cortex, amygdala, and lateral hypothalamus in monkey operant feeding behavior. J. Neurophysiol. 57: 1060-1077. 
Fuster, J. M., and J. P. Jervey (1982) Neuronal firing in the inferotemporal cortex of the monkey in a visual memory task. J. Neurosci. 2: $361-375$

Geschwind, N. (1965) Disconnexion syndromes in animals and man. Brain 88: 237-294.

Geschwind, N. (1982) Disorders of attention: A frontier in neuropsychology. Phil. Trans. R. Soc. London [Biol.] 298: 173-185.

Gloor, P. (1960) Amygdala. In Handbook of Physiology, Neurophys iology, Vol. 2, J. Field, ed., pp. 1395-1420, American Physiological Society, Washington, D.C.

Gloor, P., A. Olivier, L. F. Quesney, F. Andermann, and S. Horowitz (1982) The role of the limbic system in experiential phenomena of temporal lobe epilepsy. Ann. Neurol. 12: 129-144.

Goddard, G. V. (1964) Functions of the amygdala. Psychol. Bull. 62: 89-109.

Gross, C. G., D. B. Bender, and C. E. Rocha-Miranda (1969) Visual receptive fields of neurons in inferotemporal cortex of the monkey. Science 166: 1303-1306.

Gross, C. G., C. E. Rocha-Miranda, and D. B. Bender (1972) Visual properties of neurons in inferotemporal cortex of the macaque. $J$. Neurophysiol. 35: 96-111.

Gross, C. G., D. B. Bender, and G. L. Gerstein (1979) Activity of inferior temporal neurons in behaving monkeys. Neuropsychologia 17: 215-229.

Halgren, E., R. D. Walter, D. G. Cherlow, and P. H. Crandall (1978) Mental phenomena evoked by electrical stimulation of the human hippocampal formation and amygdala. Brain 101: 83-117.

Heath, R. G., R. R. Monroe, and W. A. Mickle (1955) Stimulation of the amygdaloid nucleus in a schizophrenic patient. Am. J. Psychiatry $111: 862-863$.

Herzog, A. G., and G. W. Van Hoesen (1976) Temporal neocortical afferent connections to the amygdala in the rhesus monkey. Brain Res. 115: 57-69.

Horel, J. A., E. G. Keating, and L. J. Misantone (1975) Partial KlüverBucy syndrome produced by destroying temporal neocortex or amygdala. Brain Res. 94: 347-359.

Isaacson, R. L. (1982) The Limbic System, Plenum, New York.

Iwai, E., and M. Mishkin (1969) Further evidence on the locus of the visual area in the temporal lobe of the monkey. Exp. Neurol. 25:585594.

Iwai, E., and M. Yukie (1987) Amygdalofugal and amygdalopetal connections with modality-specific visual cortical areas in Macaques (Macaca fuscata, M. mulatta, and $M$. fascicularis). J. Comp. Neurol. 261: 362-387.

Iwai, E., T. Nishino, and K. Yamaguchi (1986) Neuropsychological basis of a K-B sign in Klüver-Bucy syndrome produced following total removal of inferotemporal cortex of Macaque monkeys. In Emotions: Neuronal and Chemical Control, Y. Oomura, ed. pp. 299-311, Japan Scientific Press/Karger AG, Tokyo.

Jacobs, B. L., and D. J. McGinty (1972) Participation of the amygdala in complex stimulus recognition and behavioral inhibition: Evidence from unit studies. Brain Res. 36: 431-436.

Jones, B., and M. Mishkin (1972) Limbic lesions and the problem of stimulus-reinforcement associations. Exp. Neurol. 36: 362-377.

Kaada, B. R. (1972) Stimulation and regional ablation of the amygdaloid complex with reference to functional representations. In The Neurobiology of the Amygdala, B. E. Eleftheriou, ed., pp. 205-281, Plenum, New York.

Kapp, B. S., R. C. Frysinger, M. Gallagher, and J. Haselton (1979) Amygdala central nucleus lesions: Effects on heart rate conditioning in the rabbit. Physiol. Behav. 23: 1109-1117.

Kapp, B. S., M. Gallagher, M. D. Underwood, C. L. McNall, and D. Whitehorn (1982) Cardiovascular responses elicited by electrical stimulation of the amygdala central nucleus in the rabbit. Brain Res. 234: 251-262

Klüver, H., and P. C. Bucy (1939) Preliminary analysis of functions of the temporal lobes in monkeys. Arch. Neurol. Psychiatr. 42: 9791000 .

Krettek, J. E., and J. L. Price (1978) Amygdaloid projections to subcortical structures within the basal forebrain and brainstem in the rat and cat. J. Comp. Neurol. 178: 225-254.

Masserman, J. H., M. LeVitt, T. McAvoy, A. Kling, and C. Pechtel (1958) The amygdalae and behavior. Am. J. Psychiatry 115: 14-17.

McGowan, B. K., W. G. Hankins, and J. Garcia (1972) Limbic lesions and control of the internal and external environment. Behav. Biol. 7 : 841-852.
Mishkin, M. (1978) Memory in monkeys severely impaired by combined but not by separate removal of amygdala and hippocampus. Nature 273: 297-298.

Mishkin, M. (1982) A memory system in the monkey. Phil. Trans. R. Soc. London [Biol.] 298: 85-95.

Mishkin, M., and J. Aggleton (1981) Multiple functional contributions of the amygdala in the monkey. In The Amygdaloid Complex, Y. BenAri, ed., pp. 409-420, Elsevier/North-Holland Biomedical, Amsterdam.

Nachman, M., and J. H. Ashe (1974) Effects of basolateral amygdala lesions on neophobia, learned taste aversions, and sodium appetite in rats. J. Comp. Physiol. Psychol. 87: 622-643.

Nakano, Y., L. Lenard, Y. Oomura, H. Nishino, S. Aou, and T. Yamamoto (1987) Functional involvement of catecholamines in reward related neuronal activity of the monkey amygdala. J. Neurophysiol. 57: 72-91.

Nauta, W. J. H. (1961) Fibre degeneration following lesions of the amygdaloid complex in the monkey. J. Anat. 95: 515-531.

Nishijo, H., T. Ono, K. Nakamura, M. Kawabata, and K. Yamatani (1986) Neuron activity in and adjacent to the dorsal amygdala of monkey during operant feeding behavior. Brain Res. Bull. 17: 847854.

Nishijo, H., T. Ono, and H. Nishino (1988) Topographic distribution of modality-specific amygdalar neurons in alert monkey. J. Neurosci. 8: $3556-3569$.

O'Keefe, J., and H. Bouma (1969) Complex sensory properties of certain amygdala units in the freely moving cat. Exp. Neurol. 23:384398.

Ono, T., H. Nishino, K. Sasaki, M. Fukuda, and K. Muramoto (1980) Role of the lateral hypothalamus and the amygdala in feeding behavior. Brain Res. Bull. (Suppl. 4) 5: 143-149.

Ono, T., M. Fukuda, H. Nishino, K. Sasaki, and K. Muramoto (1983) Amygdaloid neuronal responses to complex visual stimuli in an operant feeding situation in the monkey. Brain Res. Bull. 11: 515-518.

Ono, T., P. G. M. Luiten, H. Nishijo, M. Fukuda, and H. Nishino (1985) Topographic organization of projections from the amygdala to the hypothalamus of the rat. Neurosci. Res. 2: 221-239.

Ono, T., K. Nakamura, H. Nishijo, and M. Fukuda (1986) Hypothalamic neuron involvement in integration of reward, aversion, and cue signals. J. Neurophysiol. 56: 63-79.

Oomura, Y. (1980) Input-output organization in the hypothalamus relating to food intake behavior. In Physiology of the Hypothalamus, Handbook of the Hypothalamus, Vol. 2, P. J. Morgane and J. Panksepp, eds., pp. 557-620, Marcel Dekker, New York.

Oomura, Y., T. Ono, and H. Ooyama (1970) Inhibitory action of the amygdala on the lateral hypothalamic area in rats. Nature 228: $1108-$ 1110.

Perrett, D. I., E. T. Rolls, and W. Caan (1982) Visual neurons responsive to faces in the monkey temporal cortex. Exp. Brain Res. 47 329-342.

Pribram, K. H., and D. McGuinness (1975) Arousal, activation, and effort in the control of attention. Psychol. Rev. 82: 116-149.

Rolls, E. T. (1981) Processing beyond the inferior temporal visual cortex related to feeding, memory, and striatal function. In Brain Mechanisms of Sensation, Y. Katsuki, R. Norgren, and M. Sato., eds., pp. 241-269, Wiley, New York.

Rolls, E. T., S. J. Judge, and M. K. Sanghera (1977) Activity of neurons in the inferotemporal cortex of the alert monkey. Brain Res. 130 . 229-238.

Sanghera, M. K., E. T. Rolls, and A. Roper-Hall (1979) Visual responses of neurons in the dorsolateral amygdala of the alert monkey. Exp. Neurol. 63: 610-626.

Sarter, M., and H. J. Markowitsch (1985) The amygdala's role in human mnemonic processing. Cortex 21:7-24.

Sato, T., T. Kawamura, and E. Iwai (1980) Responsiveness of inferotemporal single units to visual pattern stimuli in monkeys performing discrimination. Exp. Brain Res. 38: 313-319.

Sawa, M., and J. M. R. Delgado (1963) Amygdala unitary activity in the unrestrained cat. Electroencephalogr. Clin. Neurophysiol. 15:637650 .

Spiegler, B. J., and M. Mishkin (1981) Evidence for the sequential participation of inferior temporal cortex and amygdala in the acquisition of stimulus-reward associations. Behav. Brain Res. 3: 307-317.

Turner, B. H., M. Mishkin, and M. Knapp (1980) Organization of the amygdalopetal projections from modality-specific cortical association areas in the monkey. J. Comp. Neurol. 191: 515-543. 
Weiskrantz, L. (1956) Behavioral changes associated with ablation of the amygdaloid complex in monkeys. J. Comp. Physiol. Psychol. 49: 381-391.

Weiskrantz, L., and R. C. Saunders (1984) Impairments of visual object transforms in monkeys. Brain 107: 1033-1072.

Yamamoto, T., S. Azuma, and Y. Kawamura (1981) Significance of cortical-amygdalar-hypothalamic connections in retention of conditioned taste aversion in rats. Exp. Neurol. 74: 758-768.
Zola-Morgan, S., and L. R. Squire (1984) Preserved learning in monkeys with medial temporal lesions: Sparing of motor and cognitive skills. J. Neurosci. 4: 1072-1085.

Zola-Morgan, S., L. R. Squire, and M. Mishkin (1982) The neuroanatomy of amnesia: Amygdala-hippocampus versus temporal stem. Science 218: 1337-1339. 